\title{
On Discourse Translation from the Perspective of Theme and Rheme
}

\author{
Xu Jun \\ South China Business College, Guangdong University of Foreign Studies, Guangzhou, China \\ Email address: \\ 6869471@qq.com \\ To cite this article: \\ Jun Xu. On Discourse Translation from the Perspective of Theme and Rheme. Science Journal of Education. Vol. 7, No. 1, 2019 , pp. $24-29$. \\ doi: $10.11648 /$ j.sjedu.20190701.15
}

Received: April 12, 2019; Accepted: May 20, 2019; Published: May 23, 2019

\begin{abstract}
In the late 1930s, VilemMathesius, founder the Prague Linguistic Circle, put forward the concept of Theme and Rheme. Later, in 1960s, Jan Firbas, member of the Prague Linguistic Circle, proposed Communicative Dynamism (CD), which is based on context. Many domestic and foreign scholars have done lots of research on the theme and rheme of English from the aspect of sentence, but seldom discuss and verify the concept of theme and rheme from the perspective of text or context. Based on theme and rheme, communicative dynamism (CD) and the language differences between English and Chinese, this paper focuses on the influence of context on the $\mathrm{CD}$ value of the theme and rheme and analyzes the coherence of English and Chinese translation from the perspective of context.Through the above analysis, we can safely draw the conclusion that the psychological theme is not necessarily the core of thematic progression according to its function of CD. And psychological theme of discourse may also be the premise of speech but not the progressed information $(\mathrm{CD}+)$. With the comparison and contrast between English version and Chinese version, the following research would hope to distinguishbetween Chinese discourse progressing and its English counterparts.
\end{abstract}

Keywords: Theme, Rheme, Communicative Dynamism, Discourse Translation

\section{Introduction}

Due to the language differences in sentence structure, mode of expression and thinking between English and Chinese, some difficulties are often encountered in translation, such as the target language not conforming to Chinese expression habit in English-Chinese translation and hard to memorize and interpret long sentences in simultaneous interpretation. From the perspective of sentence structure, English is a subject-prominent language, while Chinese topic-prominent [1]; In terms of expression, English focuses on hypotaxis, Chinese on parataxis [8]; What's more, English belongs to linear thinking from general to specific, while Chinese spiral or circular from specific to general [7]. It is believed that the analysis of the two languages'expression and discourse construction from the perspective of theme and rheme, based on the above linguistic differences, is not only helpful to judge the author's writing trend, but also conductive to translate the source language into authentic target one. According to the recent Chinese language studies, the structure of Chinese discourse features GTS (General Topic
Structure), P-clause (Punctuation Clause) as the smallest unit. In Chinese discourse, different from English, the clause usually begins without a subject but immediate the unknown information (theme in English). However, in translation from Chinese to English, the omitted subject should be complemented as a whole. From the structure difference, the progression of discourse differs apparently.

\section{Literature Review}

Contrastive research on English and Chinese Languages can trace back to 1904, when JulinKhedau Yen-Fuh published English Grammar Explained in Chinese.After that, many scholars abroad and at home contributed themselves to the study of the two languages. In 1941, B.L Whorf, an American linguist, first put forward "contrastive linguistics" in his book Language and Logic. In 1942, Shuxiang L. commented that only through comparing can we find the similarities and differences as well between languages. The early contrastive research of English and Chinese mainly based on linguistics and grammar. Due to the fact of lacking 
theoretical guidance in Chinese language, English based on western theories is always the fiduciary object for the study of Chinese language. The word order of Chinese is determined by pragmatic rather than syntactic constraints [10]. Because of the language differences between English and Chinese, the function of sentence elements cannot be equal. According to English grammar, the subject is syntactically clear, usually located at the beginning, while it differs in Chinese or is uncertain but commonly accepted as "topic" followed by "comment" [12]. In recent years, some scholars did some research about "topic" in Chinese discourse (Liulin, Y., 2003; Linjun, L, 2010; Ligang, L., 2012). Different from English subject, the topic in Chinese discourse could be noun, verb or verb phrase, preposition phraseor clause [9].

\section{Theoretical Framework}

In 1939, V. Mathesius, using functional analysis, put forward the two terms of theme and rheme, which are different from the traditional partition of subject and predicate. Mathesius called this kind of partition as "actual sentence division", which later became known as "functional sentence perspective (FSP)". In Mathesius's view, the "theme" refers to the element at the beginning of the sentence that leads to the topic, and belongs to the given message or old information, and the "rheme" refers to the element other than the theme, which is the new message. Of course, the definition of theme has been deeply discussed by many later scholars to conclude that theme is not necessarily known or given information. Halliday[4], during segmenting the semantic meaning based on information structure, holds that theme is the starting point of information, central topic of a clause, while rheme is other than the theme in the clause, providing new information about the theme. In 1974, Danes [2] put forward an important discourse coherence theory - thematic progression, which regards theme as the starting point of clauses. Through the progression of themes, the discourse is developed. Communicative Dynamism (CD) is a core concept of FSP proposed by Firbas of Prague Linguistic Circle in 1966, which studies the contribution of each component of sentences to the development of communication. Context is an important part of it. The CD value of each component in a sentence is its actual contribution to the development of communication, that is, the role of promoting the development of communication [3]. That is to say, the more a component can push communication forward, the closer it is to the node of communication, the greater its contribution is, the higher the $\mathrm{CD}$ value is, and the lower otherwise. $\mathrm{CD}$ is dynamic rather than static.

Theme and rheme belong to syntactic category, which CD the category of pragmatics. Since language is usually produced in a certain context, only the context taken into consideration can it express its meaning accurately. In discourse translation, only through analyzing the $\mathrm{CD}$ value of each component of sentence can we tell topic and comment (supporting statement)from theme and rheme.

\section{Information Transfer in Translation}

The information structure is decoder-oriented for the listener, while the thematic structure is the encoder-oriented for the speaker or author. In terms of realization, the information structure is realized by the intonation or context, while the thematic structure is reflected by the word order in the sentence.

About the information contained in the theme, Mathesius claims that the theme conveys known information, but later Halliday, Xv Shengheng, Zhu Yongsheng and other domestic and foreign scholars argue that the theme also conveys new information. Among them, Xv Shengheng[11] holds that there are five kinds of thematic information: known information, partial known information, relevant information, new information and guiding role (zero information); Zhu Yongsheng[13] believes that there are four kinds of thematic information: zero information, known information, new information and known information plus new information.

According to the requirement of information functional equivalence, the equivalence of information substantive meaning is higher than that in form. Based on the views of scholars at home and abroad, this paper analyzes the translation of three categories of thematic information: known information, unknown information and zero information.

\section{Thematic Meaning and Identification of Topic in Context}

Different from grammatical subject, theme, called psychological subject, refers to the starting point of the speaker's mind [5]. According to the analysis of Halliday, the psychological subject should be the beginning of a discourse. It is the art of expression whether known or unknown information contained in the psychological subject, while the unknown information is the right comment of the speaker about the topic. From the perspective of Communicative Dynamism and psychology, discourse progression relies more on unknown information. What's more, readers or listeners pay more attention to the unknown information of the following sentence. From this perspective, Halliday's psychology theme should be divided into utterance theme, which is located at the beginning of each sentence and can be known or unknown information, and psychological theme, referring typically the unknown information, which is exactly what the reader or listener wants to know and can be located at the beginning of each sentence or the latter part of each sentence. That is to say, utterance theme sometimes is the right psychological theme, but sometimes not. In translation, we should distinguish between the utterance theme and the psychological theme, and focus on the latter, thus to achieve accurate bilingual conversion. In general, the utterance theme and the psychological theme appear in four forms: known information first and unknown to follow, unknown information first and known to follow, just unknown information, or just relevant information (indirect information implied). 


\subsection{Thematic Meaning in Context}

Example 1:

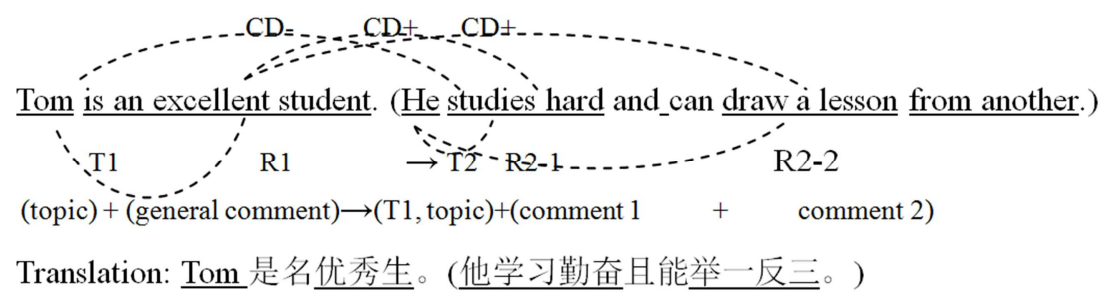

Example 2:

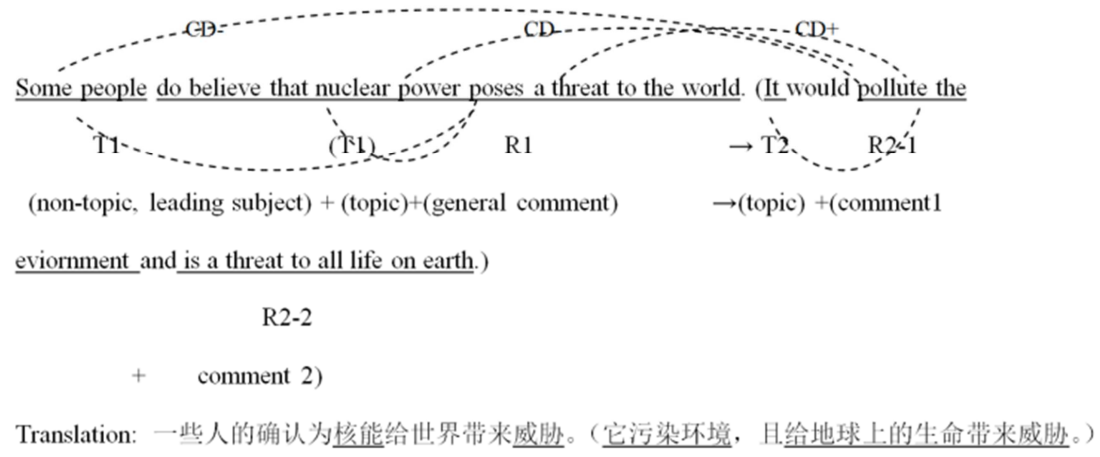

In the declarative sentence, the psychological theme, the information that the reader or listener wants to know, should be determined according to the context. The unknown information of the following sentence promotes the development of the discourse and has stronger communicative dynamism $(\mathrm{CD}+)$, so the unknown information is so-called psychological theme. The unknown information can be located at the latter part of the sentence. In example 1 and 2, Tom and nuclear powerare known information (CD-), compared to the former sentence and located at the beginning or the former part of the sentence. In this case, the theme in discourse is actually the psychological rheme, secondary information for the reader of listener. What's more, sometimes the theme of the discourse is neither the psychological theme nor the rheme, but is just a leading subject, dispensable information leading to the topic. In example 2, some peopleis the discourse theme in the former sentence, but obviously omitted in the latter sentence. However, the actual content of the latter sentence is a description of nuclear power, key words after some people in the previous part of the former sentence.

Sometimes, according to the context, the utterance theme of the latter sentence is the psychological theme, located at the beginning of the latter sentence, while the utterance theme of the former sentence becomes the utterance rheme, psychological rheme, of the latter sentence. (seeExample 3-4).

Example 3:

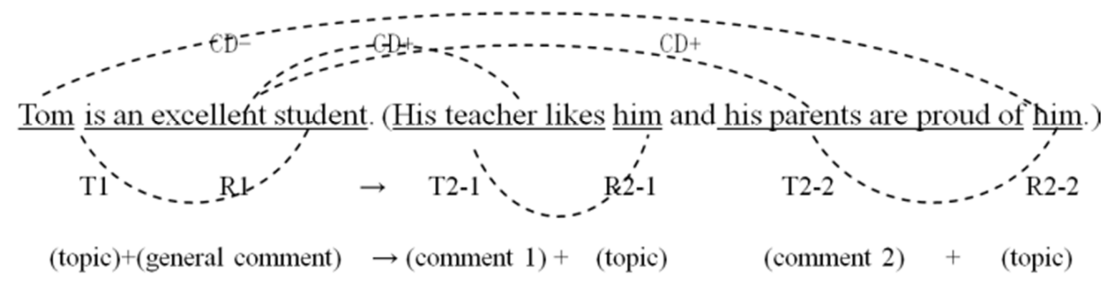

Translation: Tom 是名优秀生。老师喜欢他, 父母以他为荣。

Example 4:

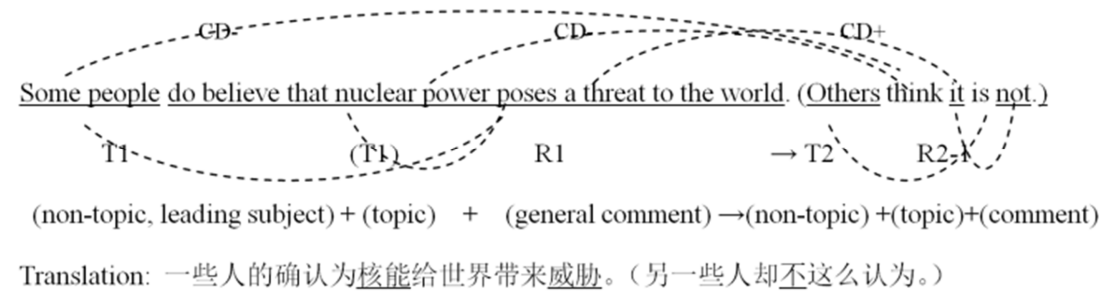


In example 3-4, compared to the former sentence, the utterance theme of the latter sentence is new information, unknown information, which promotes the development the discourse. In example 3, His teacher and his parents give further comment on excellent. Thus, the communicative dynamism of his teacher and his parents $(\mathrm{CD}+)$ is stronger than Tom. In example 4, others (CD+)express different views, whose communicative dynamism is stronger than some people.
Here, the utterance theme in the latter sentence is the real psychological theme, expected information for the reader or listener, and should be given more attention. Of course, both some people and others in example 4 are the leading subjects. The psychological theme of the discourse is the different views hold by different parts, but stronger communicative dynamism has been shown in different utterance theme, others $(\mathrm{CD}+)$ already implying the subsequent not.

Example 5:

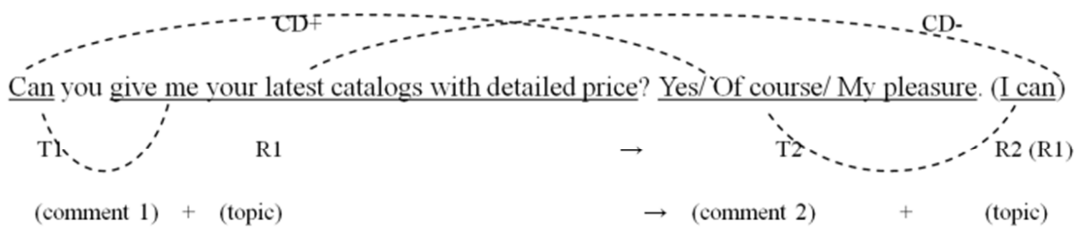

Translation: 能给我贵公司的产品且录含报价吗？当然可以。

Example 6:

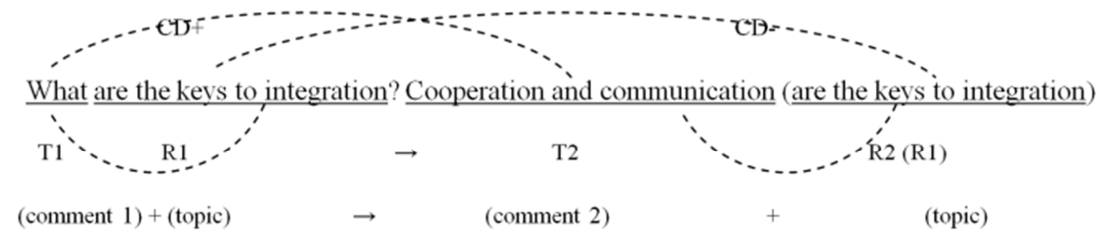

Translation: 二体化的关键是什么？合作与交流。

In the interrogative sentence, the interrogative word is the psychological theme of the interrogator, and he or she wants to get the answer, the new information, unknown one. The answer is the increase of communicative dynamism compared to the interrogative word, to promote the development of the discourse. Usually, the answer appears alone and the utterance rheme also the psychological rheme is omitted. Of course, there are times when counter-interrogative sentence has an answer already in the interrogator's mind, and there is no increase of communicative dynamism in the answer relative to the interrogative word or no need for an answer at all. In example 5-6, can and what can apparently be known as both the utterance theme and the psychological theme, compared to which yes and cooperation and communication in the latter sentence are the increase of communicative dynamism. What's more, the answer can appear independently in the latter sentence without having to follow the utterance rheme or psychological rheme (CD-).

Example 7:

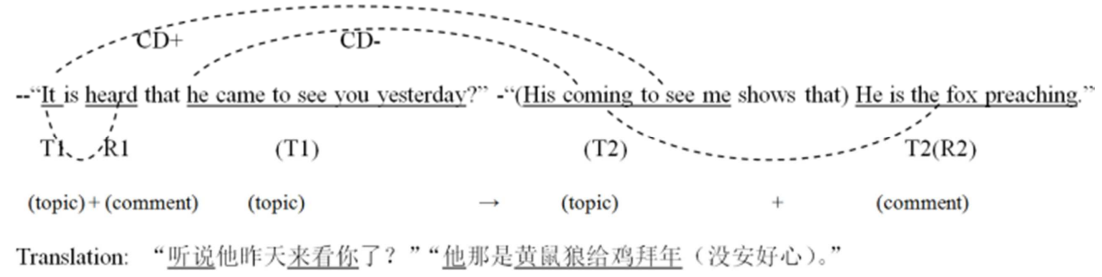

In some discourse, the following sentence or answer is not a direct development of the above but relevant, some relevant information. The seemed disconnection is contained between lines. In this case, the following relevant but not simply repeated information is new information, unknown information, which promotes the development of the discourse depending on the reader or listener's logical reasoning and association. The communicative dynamism is increased accordingly. In example 7, he came to see you is the speaker's utterance theme but psychological rheme, "he cares about you" or "what he wants you to do" implied by heard is the psychological theme of the speaker.The answer or reaction in the following sentence is naturally the result that the speaker expects to know, which is the new information, the unknown information, and the discourse is promoted, communicative dynamism increased $(\mathrm{CD}+)$. Compared with the implied psychological theme in the former sentence, the indirect answer in the latter sentence he is the fox preaching is the psychological theme. Since the known information of psychological rheme his coming to see me is omitted, the psychological theme becomes the utterance theme of the latter sentence. 


\subsection{Identification of Topic in Context}

According to Halliday, theme is the psychological subject and the starting point of the speaker's mind. Theme could be either known information or unknown information, but it is not equal to topic, which is the status or importance of a certain piece of information in a sentence in the speaker's mind. Sometimes, it is located in the beginning of the sentence. The utterance theme of the former sentence (T1) is also the utterance theme of the following sentence (T2), whose communicative dynamism becomes weaker.(see example 1) The discourse is progressed as:

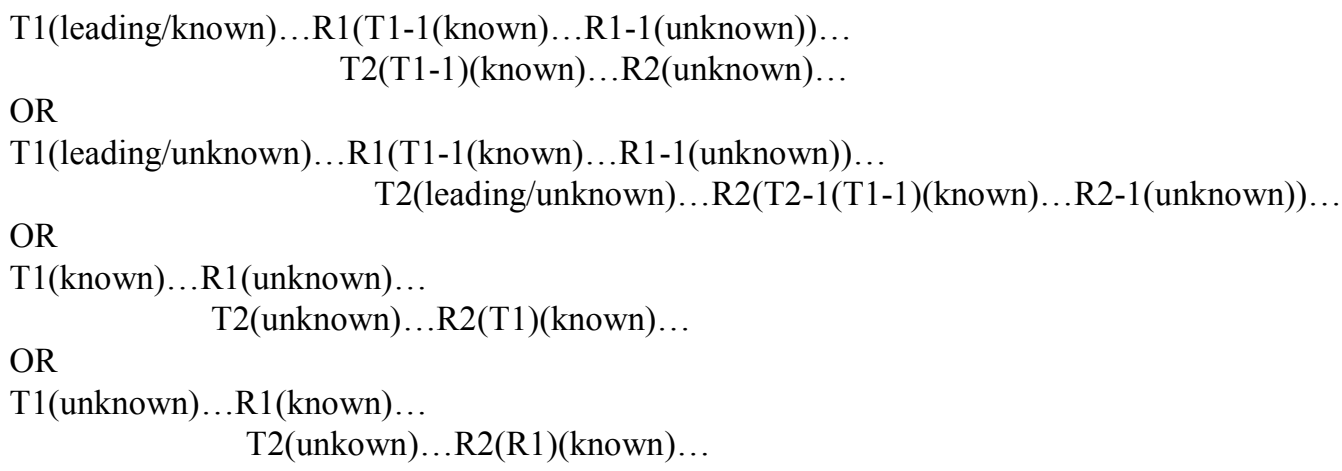

Moreover, in some cases, the psychological rheme, known information, is omitted in the following sentence. The known information could be both the utterance theme or rheme of the former sentence, and the omitted utterance theme or rheme of the following sentence. (see example 5, 6, 7) The thematic progression pattern develops as:

T1(unknown)...R1(known).. T2(unknown)...

T1(known)...R1(unknown)... T2(unknown)...

Meanwhile, topic in spoken language is mainly reflected pronunciation, intonation or speed of speech, while in written language it is embodied by the emphasis of the content in the sentence to follow.

We can safely to draw a conclusion that the known information, except leading subject, of the sentence should be the topic in context, which is also the psychological rheme for the reader or listener not expecting further information, and whose communicative dynamism becomes weaker (CD-) in the context, while those progressed with new or unknown information should be the comment, among which elements of hyponymy could be between general and specific. The position of topic could be in the front, in the middle or at the end of the sentence, and even sometimes the topic is omitted is the following sentence.

\section{Conclusion}

Based on the theories of Theme-Rheme and Communicative Dynamism, this article uses several examples to analyze the development of discourse, in which the unknown information has stronger communicative dynamism
T1(known)...R1(unknown)...

T2(T1)(known)...R2(unknown)...

In other cases, the topic is not necessarily located in the front of the sentence, sometimes in the middle (see example 2,4) and sometimes at the end of the sentence (see example 3). When there is a leading subject, such as indefinite pronouns you, we, they and generic nouns some people, others, part of R1 of the former sentence is the same as the utterance theme (T2) of the following sentence. In example 3, the utterance theme of the former sentence (T1) is the utterance rheme of the following sentence (R2). In this case, the communicative dynamism of known information becomes weaker (CD-). The discourse is progressed as: to promote the discourse, while the known information is exactly the topic of the discourse. Meanwhile, from the perspective of psychology, the psychological theme is not necessarily the utterance theme, psychological theme be speaking purpose or expectation of the speaker and utterance theme just a way to put his or her thought into discourse which is only a speaking art. In context, the discourse is developed right around the topic which is known information, and by adding more unknown information. The analysis of several examples of E-C translation aims to subdividing different thematic progression patterns, illustrating the importance of grasping the topic and distinguishing the known information from the unknown information. The examples cannot be typical for all types of English sentences, and there are always some exceptions that need to be further studied. The analysis shows that proper translation techniques, such as linear or inverted translation, adjusting word order, adding or subtracting words, conversion and annotation, should be adopted appropriately in translation to embody the speaker's speaking art as much as possible.

\section{Acknowledgements}

This study is sponsored by the 2019 Guangzhou Planning Project of Philosophical and Scientific Research "A Study on the Transformation between Topical Progression and themantic Progression from the Perspective of Cultural Self-confidence" (Grant No. 2019GZGJ206), and is part of the research of the school-level scientific research innovation team "The Innovation Team of the Comparative Study of English and Chinese Language in the New Era" (Grant No. 2018TD01). 


\section{References}

[1] Charles, N Li, Thompson, Sandra A. 1976. Subject and Topic: A New Typology of Language [C]// Charles N Li. Subject and Topic. New York: Academic Press.

[2] Danes, F. 1974. Functional Sentence Perspective and the Organization of the Text, Papers on Functional Sentence Perspective [M]. The Hague: Mouton.

[3] Firbas, J. 1966. On Defining the Theme in Functional Sentence Analysis [J]. TravauxLinguistiques de Prague.

[4] Halliday, M. A. K. 1985, 1994. An Introduction to Functional Grammar [J]. London: Edward Arnold.

[5] Halliday, M. A. K. 2008. An Introduction to Functional Grammar (revised by Christian, M. I. M. Mathiessen) [J]. Beijing: Foreign Language Teaching and Research Press.

[6] Hockett, C. F. 1958. A Course in Modern Linguistics [M]. New York: Macmillan.

[7] Kaplan, Robert B. 1966. Cultural Thought Patters in Inter-cultural Education, in Language Learning [J]. New Jersey: Addison-Wesley Publishing Company.

[8] Li, W. 1984. Chinese Grammar Theory [M]. Beijing: Zhonghua Book Company.

[9] Qianqian, Z. 2017. The Distribution Performance of Topic Structures in Chinese. [D]. Shanghai: Shanghai International Studies University.

[10] Rong, C. 1995. Communicative Dynamism and Word Order in Mandarin Chinese [J]. Great Britain: Language Science.

[11] Shengheng, X. 1985. Identification of the Theme and the Rheme [J]. Beijing: Foreign Language Teaching and Research.

[12] Yan, L. 2008. On Theme, Subject and Topic [J]. Qufu: Modern Chinese.

[13] Yongsheng, Z. 1995. Thematic Progression Pattern and Discourse Analysis [C]. Beijing: Foreign Lanuage Teaching and Research.

\section{Biography}

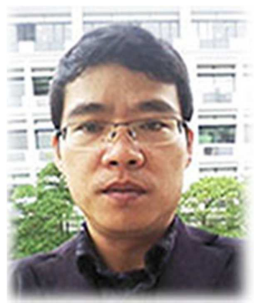

Xu Jun, born in 1977, Master of Arts, Lecturer, his research interest includes translation theory and practice. 